\title{
Possibilidades de aplicação do enfoque estratégico de planejamento no nível local de saúde: análise comparada de duas experiências
}

\author{
Applicability of the strategic planning approach \\ to local health organizations
}

Elizabeth Artmann 1

Creuza da Silva Azevedo 1

Marilene de Castilho Sá 1

\footnotetext{
1 Departamento de Administração e Planejamento em Saúde Escola Nacional de Saúde Pública, Fundação Oswaldo Cruz. Rua Leopoldo Bulhões 1480, Rio de Janeiro, RJ 21041-210, Brasil.
}

\begin{abstract}
This paper presents the preliminary results from a study on the limits and possibilities of the strategic planning approach for local health organizations. A comparative analysis is devel oped between two experiences concerning the application of the strategic situational planning method (PES method) in the management of a health center and hospital. Questions include the foll owing: difficulties with the use of the category actor in local health organizations; possibility of drafting a collective project based on the multiple rationaliti es existing in such organizations; possibility of improving communications processes with the use of the PES method; difficulties related to organizational culture; and low level s of responsibility, as well as difficulties pertaining to the method's complexity and the possibility of simplifying it, maintaining strategic situational analysis and improving organizations' managerial capacity.

Key words Health Planning; Strategic Planning; Public Health
\end{abstract}

Resumo Este artigo apresenta os resultados prel iminares de uma pesquisa sobre os li mites e possi bil i dades de apli cação do enfoque de planej amento estratégico em organizações de saúde de nível local. Desenvolve-se uma anál ise comparada de duas experiências de adoção do método de Planejamento Estratégi co-Situacional (PES) para a gestão de um Centro de Saúde e de uma unidade hospitalar. Entre as questões discuti das destacam-se: a de dificul dade de aplicação da categoria ator no nível local de saúde; a possi bilidade de construção de um projeto col etivo a partir da multiplicidade de raci onali dades presentes em organizações de saúde; a possi bilidade de se ampliarem os processos comuni cativos a partir da adoção do PES; as di ficuldades relativas à cultura organizacional e aos baixos níveis de responsabilidade, além daquelas inerentes à complexidade do método, eà possi bilidade de si mplificá-lo, garantindo-se a análi se estratégicasituacional ea ampliação da capaci dade gerencial das organizações.

Palavras-chave Planejamento em Saúde; Planejamento Estratégico; Saúde Pública 


\section{Introdução}

Este artigo é resultado de um projeto de pesquisa que vem sendo por nós desenvolvido em função, principalmente, de duas preocupações: a primeira está relacionada com a especificidade das organizações de saúde e dos problemas de saúde e a conseqüente necessidade de um enfoque metodológico de planejamento adaptado a esta especificidade; a segunda, considerando a urgência de se avançar no processo de descentralização do SUS, tem a ver com a necessidade de um enfoque de planejamento adaptado ao nível local de saúde.

A rigor, tais preocupações já estavam presentes em trabal hos anteriores e remetem às reflexões desenvolvidas em nossas teses de Mestrado (Artmann, 1993; Azevedo, 1993; e Sá, 1993), mas foi a partir de maio de 1995 que se iniciou uma investigação mais sistemática sobre os limites e possibilidades de aplicação do enfoque estratégico de planejamento no nível local de saúde, envolvendo o Centro de SaúdeEscola Germano Sinval Faria (CSEGSF), da Escola Nacional de Saúde Pública/Fiocruz, e um hospital do Ministério da Saúde localizado no Rio de Janeiro, o Hospital Raphael de Paula e Souza (HRPS).

A escolha do CSEGSF como um dos focos de análise se deu pela articulação das atividades de pesquisa e docência, atendendo simultaneamente a uma demanda antiga do CSE por assessoria. O CSE faz parte da estrutura da Escola Nacional de Saúde Pública (Ensp) desde 1968, tendo sido criado com o objetivo de servir à Escola como campo de prática para o ensino e a pesquisa. Hoje, atendendo a uma população de cerca de trinta mil habitantes, predominantemente residentes em favelas, no bairro de Manguinhos, o CSE procura fortalecer seu caráter de unidade integrante de uma instituição de Ciência e Tecnologia como a Fiocruz, desenvolvendo sua atividade de assistência como base para o desenvolvimento de linhas de pesquisa, novas tecnologias em saúde e também para a formação de recursos humanos no campo da Saúde Coletiva (Tavares et al., 1996; Fonseca, 1996).

Concomitantemente, através de Cooperação Técnica entre a Ensp e um hospital do Ministério da Saúde localizado no Rio de Janeiro, o Hospital Raphael de Paula Souza (HRPS), criaram-se as condições para a ampliação dos objetos de estudo, reforçando o caráter comparativo da pesquisa, o que, até então, só havia sido possível por meio da análise de relatos de experiências.

O HRPS foi inaugurado em 1952, tendo como missão ser um hospital voltado para tisio- logia e cirurgia torácica, vinculado ao Ministério da Saúde e posteriormente inserido na chamada Campanha de Combate à Tuberculose. Sofreu progressiva desativação dos leitos de tisiologia e implantação do tratamento ambulatorial, passando então a operar voltado para atendimento de outras pneumopatias. Na década de 80, tentou-se transformá-lo em hospital de clínicas básicas, recebendo uma maternidade, que foi posteriormente desativada no Governo Collor, sendo reaberta em 94, quando passou a ser administrada em regime de cogestão com a Secretaria Municipal de Saúde. Atualmente, o HRPS conta com 150 leitos e atendimento ambulatorial em pneumologia, Aids, clínica médica, pediatria, ginecologia, obstetrícia, neonatologia, cirurgia geral e de tórax.

Nossa investigação tem os seguintes objetivos: examinar os limites e possibilidades de aplicação do enfoque de Planejamento Estratégico no nível local de saúde; testar propostas metodológicas adaptadas à especificidade do nível local; desenvolver o método de Planejamento Estratégico no sentido de incorporar categorias analíticas, conceitos operacionais e outros instrumentais mais compatíveis com os problemas de saúde; investigar as possibilidades e limites do PES com relação às particularidades das organizações de saúde e contribuir para ampliar a capacidade gerencial das instituições envolvidas.

Até o momento, o trabalho está centrado na abordagem do Planejamento Estratégico-Situacional de Carlos M atus, especialmente na compreensão comunicativa aportada por Rivera (1995). Soma-se a este enfoque, a compreensão relativa às particularidades das organizações de saúde, enquanto processo produtivo e de divisão de poder (Mintzberg, 1989) e suas conseqüências para a prática de planejamento e processos de mudança gerencial.

O enfoque de Planejamento Estratégico-Situacional - PES (Matus, 1993, 1994b e c) surge no âmbito mais geral do planejamento econômico-social e vem sendo crescentemente utilizado no campo da saúde. Parte do reconhecimento da complexidade e da incerteza da realidade social, que se assemelha a um sistema de final aberto e probabilístico, onde os problemas se apresentam, em sua maioria, não estruturados e o poder se encontra compartido. Matus (1993), apoiado em Ian Mitroff, utiliza as noções de problemas bem estruturados, quase estruturados e não estruturados. Os primeiros são problemas que, em geral, podem ser tratados segundo modelos determinísticos de análise, pois se conhecem todas as variáveis inter- 
venientes e suas formas de articulação. Por outro lado, os dois outros tipos de problemas só podem ser tratados a partir de modelos probabilísticos e de intervenções criativas, já que fazem parte de situações de incerteza quantitativa e/ ou qualitativa, nas quais não se podem enumerar todas as variáveis envolvidas e seus respectivos pesos na geração do problema.

Para enfrentar tal complexidade, o Método se apóia em um enfoque teórico bastante consistente, do qual podem ser destacados os seguintes elementos:

- O conceito de situação e de explicação situacional, onde a situação é um recorte problemático da realidade feito por um ator em função de seu projeto de ação e é constituída pelo ator-eixo da explicação situacional, por outros atores, pelas suas ações, e pelas estruturas econômica, política, ideológica, social etc.

- A Teoria da Produção Social, que explica a realidade para além dos fatos mais aparentes, através de três níveis: o nível dos fatos propriamente ditos ou fenoprodução (fatos de qualquer natureza), o nível das acumulações ou fenoestruturas (capacidades de produção) e o nível das regras ou leis básicas que regulam uma formação social. Os diferentes processos e fenômenos da real idade articulam-se dinamicamente, tanto no interior de cada um desses níveis, como entre eles, havendo uma maior determinação do último nível - as regras - sobre os demais. A aplicação concreta desta teoria se dá no momento de explicação de um problema quando, através da montagem do Fluxograma Situacional, localizam-se as causas nesses três níveis, estabelecendo-se uma rede de relações causais, o que contribui para uma visão mais ampla do problema explicado e, conseqüentemente, para uma atuação mais efetiva.

- A Teoria da Ação, que distingue uma forma de ação não interativa, instrumental ou comportamental - própria do planejamento normativo - e aplicável a problemas bem-estruturados, e uma forma de ação interativa, referida ao espaço social e político, que fundamenta a necessidade do cálculo interativo ou raciocínio estratégico - aplicável a problemas quase-estruturados.

- O conceito de momento, formulado para superar a idéia de 'etapas' rígidas, implicando uma visão dinâmica do processo de planejamento, que se caracteriza pela permanente interação de suas fases ou momentos e pela constante retomada dos mesmos. O Método PES prevê quatro momentos para o processamento técnicopolítico dos problemas: os momentos explicativo, normativo, estratégico e tático-operacional. Cada um desses momentos possui suas ferra- mentas metodológicas específicas, que podem, no entanto, ser retomadas nos demais.

- A Teoria das Macroorganizações, onde Matus (1994a) aplica a Teoria da Produção Social à análise das organizações, permitindo-nos avaliá-las, seja através de seus fluxos de produção, suas acumulações ou das regras que as regem (regras de direcionalidade, departamentalização, governabilidade e responsabilidade). Desta forma, oferece maneiras de se pensar a reforma organizacional.

Aliado a este enfoque, utilizamos, para nos aproximarmos da especificidade e complexidade das organizações de saúde, de outro referencial teórico, conformado especialmente pelo trabalho de Mintzberg (1989), cuja produção inclui a compreensão do mundo organizacional e a definição de uma tipologia das organizações.

As organizações de saúde, particularmente os hospitais, são identificados em sua tipologia como organizações profissionais, caracterizando-se por sua grande dependência dos profissionais responsáveis pela execução das atividades finalísticas da organização. Estas atividades, devido a sua complexidade, são executadas e controladas diretamente por esses profissionais, especialistas com alto nível de qualificação, que requerem autonomia para o desenvolvimento de seu trabalho.

Como o processo de trabalho é muito complexo e especializado, os resultados do trabaIho profissional não podem ser mensurados facilmente. As decisões, em grande parte, dependem de julgamento profissional. O poder em organizações deste tipo advém essencialmente dos experts, sendo conseqüência da perícia e não da hierarquia. Neste contexto, o papel dos gerentes/ planejadores é mais limitado para coordenar ou normalizar o trabalho profissional. Além disso, destaca-se o desafio de integração da dupla estrutura, profissional e administrativa, bem como entre os diversos especialistas, principalmente no sentido do compromisso com os objetivos organizacionais.

A partir da compreensão de Mintzberg, evidencia-se a particularidade da distribuição de poder nas organizações de saúde, onde os profissionais jogam importante papel em sua dinâmica. Como conseqüência, torna-se claro que as estratégias gerenciais devem incluir processos participativos, de negociação e comunicação intensa com os diversos grupos internos (Azevedo, 1995).

A estas discussões, somam-se nossas preocupações com a complexidade dos problemas de saúde (Sá, 1993; Sá \& Artmann, 1994). Aqui destacam-se duas ordens de questões. Por um 
lado, as diferentes formas de representação, valoração e compreensão dos problemas de saúde pelos diversos grupos sociais envolvidos, incluindo a população, o que apresenta, como um dos principais desafios, a necessidade de articulação das diferentes racionalidades envolvidas em um processo concreto de planejamento. Por outro lado, a particular complexidade dos fenômenos, processos e leis que caracterizam a realidade sanitária aponta para diversas possibilidades de 'recorte' desses problemas, em termos de unidades de análise e intervenção. Cada uma dessas possibilidades de recorte apresenta distintas implicações operacionais sobre a capacidade de apreensão e compreensão das necessidades de saúde, bem como de cumprimento dos princípios de eqüidade e integralidade.

A partir deste marco de referência, foram levantadas algumas questões que têm servido de base para as reflexões teórico-metodológicas de nossa investigação, embora nem todas tenham sido desenvolvidas plenamente até o momento. 1) Quem são os atores que planejam em organizações de saúde em nível local? Do ponto de vista operacional, encontramos certa dificuldade em aplicar no nível local a categoria ator, de Matus, que exige a combinação de três critérios: representatividade ou base organizativa, controle de recursos relevantes para a situação e projeto político definido.

Nesta mesma perspectiva, e considerando os projetos nem sempre homogêneos no interior de uma organização, as diferentes racionalidades que a perpassam e as diversas visões dos grupos de funcionários/ profissionais, até que ponto o enfoque pode contribuir para a constituição de um ator capaz de expressar um projeto coletivo?

2) Como potencializar o processo comunicativo com a utilização do PES, considerando a distribuição de poder presente em organizações de saúde?

3) Como ampliar a capacidade do método em processos onde pactuar/negociar objetivos é fundamental?

4) Como distinguir, no desenvolvimento e avaliação de experiências, entre as dificuldades inerentes ao próprio método, aquelas decorrentes da forma de utilizá-lo? A forma de aplicação do método depende tanto de capacidades cognitivas, quanto de sensibilidade para lidar com situações de impasse e para transmitir os conteúdos metodológicos.

5) Como tornar o método mais acessível sem empobrecê-lo, garantindo a riqueza da análise estratégico-situacional? Esta questão refere-se à complexidade do método versus a necessida- de de simplificá-lo para facilitar a operacionalização.

6) Como vencer o desafio de transitar, no processamento dos problemas, entre a linguagem especializada e a linguagem comum, numa perspectiva participativa?

7) Em que medida o processo e a metodologia podem favorecer a ampliação do olhar sobre os problemas de saúde?

8) Em que medida o processo favorece a articulação das diferentes racionalidades que perpassam as organizações de saúde?

O processo de aplicação do enfoque de planejamento estratégico-situacional

O quadro abaixo sintetiza a análise comparativa das experiências. Para uma melhor compreensão, é importante considerar a natureza da pesquisa - que contém uma dimensão de cooperação técnica/ assessoria, e por isso de intervenção no objeto de estudo -, bem como seus objetivos, que incluem um componente de adaptação do método. Isto faz com que, por um lado, parte das variáveis de comparação só possam ser selecionadas ao longo do processo e, por outro lado, algumas apresentem uma dupla dimensão: ao mesmo tempo em que remetem a questões teórico-metodológicas relevantes, referem-se também a características específicas dos processos nas diferentes instituições.

Inicialmente, é importante destacar algumas características que marcam diferenças com relação ao início do processo de planejamento estratégico nas duas instituições.

No caso do CSE, havia uma demanda por assessoria na área de planejamento estratégico, embora pouco definida quanto aos objetivos perseguidos. Definimos, então, como estratégia para dar início ao trabalho, a formação de um grupo mais orgânico de coordenação que, ao longo do processo, pudesse vir a se constituir na equipe de direção do CSE. A expectativa era de que a formação deste grupo pudesse se dar através da apropriação teórico-metodógica do PES e de sua aplicação. Este caminho não se revelou, no entanto, muito linear, encontrando-se este grupo ainda em fase de constituição.

Quanto ao HRPS, o início do processo de planejamento estratégico foi precedido pela inserção de uma pesquisadora da Ensp, co-autora deste artigo, na equipe de direção do hospital. A estratégia inicial do trabalho, considerando o contexto de início de gestão e da experiência de gestão colegiada, foi a de introduzir 
algumas discussões sobre o processo decisório, o sistema de direção e as dificuldades para definição de responsabilidades. Ao mesmo tempo, definiu-se a participação de dois membros da equipe de direção em um curso de gestão hospitalar oferecido pela Ensp e que adota a metodologia do PES. Junto com a direção foi amadurecido como e quando introduzir a metodologia do PES.

É importante destacar que as duas experiências tiveram como objetivo explícito elaborar um plano de ação estratégica, de forma participativa, e que pudesse contribuir para a construção da identidade do grupo de direção em torno dos problemas estratégicos das respectivas instituições (Tabela 1).

Inicialmente, pode-se observar que as duas primeiras variáveis - participantes e adesão buscam traduzir a estratégia adotada e as dificuldades para a construção de um processo mais coletivo de enfrentamento de problemas. O cumprimento das tarefas pelos participantes e seu nível de autonomia - enquanto expressões ainda que parciais da capacidade organizativa, de formulação de propostas, de adesão ao processo e responsabilidade com seu andamento - podem ser tomados como indicadores, entre outros, da construção de um ator. Esta é uma das principais questões teóricas da pesquisa, qual seja, a da possibilidade de construção de atores que expressem projetos coletivos, tendo em vista a multiplicidade de racionalidades em jogo na vida institucional, os diferentes projetos e a peculiar distribuição de poder presente em organizações de saúde.

Outro aspecto que merece destaque diz respeito ao papel do diretor no processo. Cabe lembrar que as organizações de saúde, enquanto organizações profissionais, caracterizam-se por uma situação de poder fortemente compartido, adquirindo importância a participação do conjunto de seus profissionais na determinação de seus rumos. Desta forma, a direção, neste tipo de organização, possui menor governabilidade. Observa-se, no entanto, que variações com relação ao estilo de direção e tipo de envolvimento do diretor com o processo condicionam diferenças quanto ao andamento do mesmo (adesão de outros profissionais, cumprimento das tarefas, qualidade dos resultados, por exemplo), destacando-se, portanto, o papel estratégico deste ator para viabilizar o processo.

Considerando agora o papel do assessor, vale destacar que a diferença nas formas de inserção nas duas instituições - no hospital, como membro da equipe de direção - não impe- diu que em ambas as experiências estes, além da condução metodológica, tivessem importante papel nas discussões de condução política e de conteúdo técnico. Deve ser também valorizado o papel do assessor como mediador das relações entre os membros dos grupos, destacando-se a necessidade de desenvolver sua capacidade de leitura e intervenção nos processos comunicativos/ intersubjetivos que se estabelecem. Com relação a este último aspecto, é importante salientar que, com o passar do tempo e a crescente proximidade com a vida e o cotidiano das instituições, temos vivenciado uma relativa diminuição do olhar externo do assessor e um aumento correspondente de sua vivência como membro da organização. Isto, de certo modo, pode ser vantajoso, do ponto de vista de sua legitimidade, mas pode, por outro lado, comprometer sua capacidade de mediação.

A quinta variável, que trata das estratégias adotadas para possibilitar a apropriação pela equipe do enfoque metodológico do PES, permite, em uma análise comparativa, destacar a insuficiência da estratégia de se utilizar apenas do processo de assessoria como forma de capacitação da equipe. A partir das diferenças de treinamento/formação tanto gerencial como no método PES entre as equipes das duas instituições, conclui-se pela necessidade de inserção de alguns elementos-chave em programas específicos de capacitação para efetivo aumento da capacidade de governo da equipe envolvida com o processo. A capacidade de governo, conceito trabal hado por Matus (1993), constitui-se num dos vértices de seu Triângulo de Governo (os outros dois são projeto de governo e governabilidade sobre o sistema) e se expressa, em nível organizacional, no conjunto de recursos cognitivos, tecnológicos, nas experiências das equipes e dos dirigentes, nos sistemas e métodos disponíveis etc. Os três vértices se condicionam mutuamente. Assim, por exemplo, quanto maior a capacidade de governo maior a governabilidade sobre o sistema e maior a possibilidade de implementação do projeto de governo. Nessa perspectiva, destaca-se em particular a importância de sensibilizar e capacitar os profissionais ligados à assistência, especialmente aqueles que exercem funções gerenciais, considerando-se que nos serviços de saúde depende-se, em grande medida, desses profissionais para obtenção de bons resultados.

A conjuntura institucional é uma variável que expressa características particulares das instituições, que podem condicionar o andamento dos processos. No início do processo no 
Tabela 1

Q uadro comparativo das experiências (maio de 1995 até agosto de 1996).

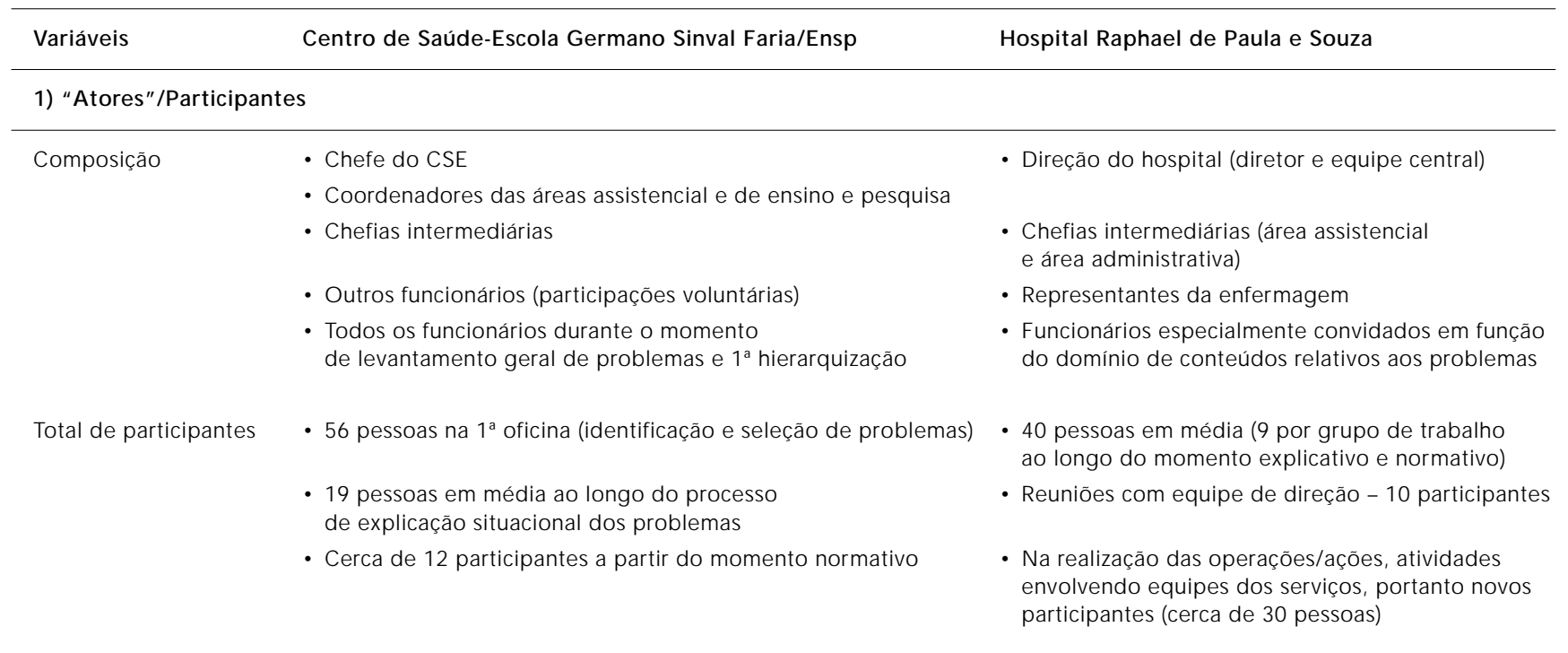

2) Adesão/Participação

Assiduidade e
cumprimento das tarefas

- Flutuações no número de participantes ao longo do processo com freqüência em geral regular às reuniões (cerca de 60\%)

- Tarefas cumpridas, embora com atrasos, até o desenho das operações. Dificuldade no cumprimento de tarefas relativas à execução das operações

Motivação para discussão

Autonomia
- Média a alta em todos os participantes no início do processo. Diminuição da motivação de alguns deles ao longo do processo

- Grupos ainda muito dependentes da orientação (e presença) das assessoras

Obs. Nenhum participante conhecia a metodologia
- Boa assiduidade no geral, com flutuações nos diferentes grupos (média de $70 \%$ de freqüência)

- Cumprimento de $100 \%$ das tarefas até o momento normativo. Dificuldade na implementação de operações

- Alta motivação domina em três dos quatro grupos de trabalho. O scilações da motivação ao longo do processo.

- Boa autonomia dos coordenadores de grupo e de uma parcela dos participantes, variando o grau de autonomia geral dos diferentes grupos Obs. Participação de alunos do curso de gestão hospitalar e residentes ( $r 2$ - estágio em gestão hospitalar)

3) Papel do diretor

\begin{tabular}{|c|c|c|}
\hline Estilo de direção & $\begin{array}{l}\text { - Pouca rigidez na cobrança de assiduidade } \\
\text { e cumprimento de tarefas }\end{array}$ & $\begin{array}{l}\text { - Cobrança de participação e do cumprimento de } \\
\text { tarefas. Alta capacidade de comunicação } \\
\text { e liderança }\end{array}$ \\
\hline Formação para gerência & $\begin{array}{l}\text { - Conhecimento de algumas experiências de planejamento } \\
\text { estratégico e pouco conhecimento sobre a metodologia } \\
\text { do PES no início do processo. Especializando-se em Curso } \\
\text { para Gerentes Locais de Saúde }\end{array}$ & $\begin{array}{l}\text { - Boa capacidade de análise estratégica; formação } \\
\text { em gestão hospitalar; conhecimento da } \\
\text { metodologia do PES através do acompanhamento } \\
\text { de algumas experiências e cursos }\end{array}$ \\
\hline $\begin{array}{l}\text { Envolvimento } \\
\text { com o processo }\end{array}$ & $\begin{array}{l}\text { - Experiências anteriores em cargos de direção/gerência } \\
\text { - Participação constante } \\
\text { - Contribuições técnicas }\end{array}$ & $\begin{array}{l}\text { - Idem } \\
\text { - Condução do processo } \\
\text { - Contribuições técnicas e na análise estratégica }\end{array}$ \\
\hline
\end{tabular}


Tabela 1 (continuação)

\begin{tabular}{|c|c|c|}
\hline Variáveis & Centro de Saúde-Escola Germano Sinval Faria/Ensp & Hospital Raphael de Paula e Souza \\
\hline \multicolumn{3}{|c|}{ 4) Papel do assessor } \\
\hline Tipo de inserção & - Assessoria à direção do CSE, sem inserção direta & $\begin{array}{l}\text { - Inserção como membro da equipe de direção } \\
\text { (ator no processo) }\end{array}$ \\
\hline Envolvimento & $\begin{array}{l}\text { - Em tempo parcial, condução geral do processo } \\
\text { de planejamento, definição de estratégias para } \\
\text { o desenvolvimento do processo, coordenação das oficinas, } \\
\text { monitoria e supervisão dos grupos de trabalho } \\
\text { de grupo }\end{array}$ & $\begin{array}{l}\text { - Cotidiano, condução geral do processo, definição } \\
\text { de estratégias de desenvolvimento do processo } \\
\text { com a Direção, pré-processamento dos problemas, } \\
\text { revisão dos produtos com os coordenadores }\end{array}$ \\
\hline $\begin{array}{l}\text { Interferência } \\
\text { no processo }\end{array}$ & $\begin{array}{l}\text { - Condução metodológica, política e participação } \\
\text { nas discussões sobre conteúdo }\end{array}$ & $\begin{array}{l}\text { - Condução metodológica, política e de } \\
\text { conteúdo/técnica }\end{array}$ \\
\hline
\end{tabular}

5) Apropriação metodológica pela equipe

\begin{tabular}{|c|c|c|}
\hline \multirow[t]{2}{*}{ Formas de capacitação } & $\begin{array}{l}\text { - Preparação de um grupo coordenador do processo: } \\
\text { quatro seminários teóricos e de discussão metodológica } \\
\text { (até Momento Explicativo) }\end{array}$ & $\begin{array}{l}\text { - Equipe de coordenação: curso na Ensp (Gestão } \\
\text { Hospitalar) e participação de residentes em Gestão } \\
\text { Hospitalar; debates com assessor sobre } \\
\text { o desenvolvimento do trabalho }\end{array}$ \\
\hline & $\begin{array}{l}\text { - Posteriormente a discussão teórico-metodológica passa } \\
\text { a integrar as oficinas de processamento dos problemas, } \\
\text { com todos os participantes. Introdução de alguns conceitos } \\
\text { simultaneamente à sua aplicação }\end{array}$ & $\begin{array}{l}\text { - Participantes: discussão teórico-metodológica } \\
\text { no início do processo } \\
\text { - debates nos grupos de trabalho sobre } \\
\text { seu desenvolvimento }\end{array}$ \\
\hline Intrumentos & $\begin{array}{l}\text { - Roteiros de trabalho e utilização de caso ilustrativo } \\
\text { de uma SMS (M. Explicativo e Normativo) }\end{array}$ & $\begin{array}{l}\text { Roteiros de trabalho com caracterização } \\
\text { e explicação dos momentos, objetivos } \\
\text { e técnicas até desenho de operações }\end{array}$ \\
\hline
\end{tabular}

6) Conjuntura institucional

\begin{tabular}{|c|c|c|}
\hline $\begin{array}{l}\text { Momento da gestão } \\
\text { e forma de acesso } \\
\text { ao cargo }\end{array}$ & $\begin{array}{l}\text { - Início do processo a seis meses do término do mandato, } \\
\text { com perspectivas de reeleição. Processo eleitoral } \\
\text { com } 3 \text { candidatos. Reeleição da Chefia por grande } \\
\text { margem de votos. Mandato de dois anos (este foi } \\
\text { o horizonte de tempo definido para o plano) }\end{array}$ & $\begin{array}{l}\text { - Início do processo no início da gestão. } \\
\text { Diretor indicado internamente, nomeado pelo MS, } \\
\text { sem mandato definido }\end{array}$ \\
\hline $\begin{array}{l}\text { Receptividade da } \\
\text { instituição à proposta }\end{array}$ & $\begin{array}{l}\text { - Inicialmente, grande receptividade à proposta; funcionários } \\
\text { e chefias com muitas expectativas. Atualmente a receptividade } \\
\text { continua boa dentro de um grupo mais restrito de participantes } \\
\text { (reconhecimento da importância do processo para maior } \\
\text { organicidade do grupo). No entanto, há dificuldades de } \\
\text { envolvimento de outros profissionais }\end{array}$ & $\begin{array}{l}\text { - Grande receptividade à proposta, com algumas } \\
\text { dificuldades em um dos grupos (até o desenho } \\
\text { de operações). Dificuldade para difundir e ampliar } \\
\text { o alcance do trabalho para além dos níveis gerenciais }\end{array}$ \\
\hline
\end{tabular}

Centro de Saúde, houve certa dificuldade de adesão de profissionais que se colocavam em oposição à direção. Ao longo do processo, houve gradativamente um aumento da adesão, ainda que no período eleitoral as relações tenham ficado mais tensas e os grupos de trabaIho mais esvaziados. Hoje observa-se um movimento de reaglutinação em torno do plano. Já no Hospital, o fato de o processo de planejamento ter começado no início da gestão do atual diretor, parece ter contribuído para uma maior adesão e agilidade.

As opções metodológicas buscaram responder às necessidades de adaptação do mé- todo para o nível local, ao mesmo tempo considerando as especificidades deste nível e procurando tornar o método mais acessível sem, contudo, empobrecê-lo.

Foram utilizadas várias técnicas que não pertencem ao PES, para facilitar a participação nos grupos de trabal ho e a busca do consenso na seleção dos problemas. Dentre estas, destacamos o Diagrama de Afinidades - uma ferramenta da abordagem da Qualidade Total - por sua utilidade no agrupamento de problemas.

Das adaptações feitas no interior do método, vale a pena destacar a introdução do exer- 
Tabela 1 (continuação)

\begin{tabular}{|c|c|c|}
\hline Variáveis & Centro de Saúde-Escola Germano Sinval Faria/Ensp & Hospital Raphael de Paula e Souza \\
\hline \multicolumn{3}{|c|}{ 7) Opções metodológicas mais relevantes (até agosto de 1996) } \\
\hline \multirow[t]{7}{*}{ Momento explicativo } & $\begin{array}{l}\text { - Exposição e discussão da situação atual do CSE } \\
\text { e das condições de saúde da população da área }\end{array}$ & $\cdot-$ \\
\hline & - Construção de uma imagem de futuro & - Idem \\
\hline & $\begin{array}{l}\text { - Levantamento de problemas através da técnica de } \\
\text { brainstorm, considerando a imagem de futuro construída. }\end{array}$ & - Idem \\
\hline & $\begin{array}{l}\text { - Agrupamento dos problemas através da } \\
\text { técnica de Diagrama de Afinidades }\end{array}$ & - Idem \\
\hline & $\begin{array}{l}\text { - Seleção dos problemas a serem enfrentados, através da } \\
\text { técnica de grupo nominal, adaptada, e do Protocolo de } \\
\text { Seleção proposto por Matus, com adaptações }\end{array}$ & - Idem \\
\hline & $\begin{array}{l}\text { - Explicação dos problemas com utilização das noções } \\
\text { de regras, acumulações e fluxos de forma simplificada }\end{array}$ & $\begin{array}{l}\text { - Utilização das noções de causas diretas e indiretas, } \\
\text { com a Teoria da Produção Social implícita }\end{array}$ \\
\hline & $\cdot-$ & $\begin{array}{l}\text { - Análise estratégica informal, considerando o } \\
\text { contexto, para desencadear algumas ações } \\
\text { estratégicas e implementação de ações menos } \\
\text { sensíveis aos cenários }\end{array}$ \\
\hline Momento normativo & $\begin{array}{l}\text { - Mesa redonda, com convidados representativos de grupos } \\
\text { de variáveis mais importantes, para a construção dos cenários }\end{array}$ & $\begin{array}{l}\text { - Discussão com um representante do MS sobre } \\
\text { variáveis relevantes para a construção dos cenários. }\end{array}$ \\
\hline & & $\begin{array}{l}\text { - Apresentação da proposta de Reforma } \\
\text { Administrativa do Governo Federal }\end{array}$ \\
\hline \multirow[t]{2}{*}{ Momento estratégico } & - Implementação de algumas ações menos sensíveis aos cenários & - Idem \\
\hline & $\begin{array}{l}\text { - Construção dos cenários (otimista, central e pessimista) com } \\
\text { um grupo menor, de maior adesão ao processo }\end{array}$ & \\
\hline $\begin{array}{l}\text { Momento } \\
\text { tático-operacional }\end{array}$ & - Ainda não iniciado & $\begin{array}{l}\text { - Bem desenvolvido para o problema mais } \\
\text { estratégico (objetivos) }\end{array}$ \\
\hline
\end{tabular}

8) Organização/Dinâmica do processo

- Seminários de discussão teórico-metodológica com grupo de coordenação (início do processo)

- Oficinas para a seleção e processamento dos problemas, as primeiras com todos os funcionários e as demais com grupos de trabalho

- Diluição dos grupos de trabalho em um só grupo, a partir do momento normativo, por insuficiência de pessoal. Retomada da organização por grupos de trabalho a partir de junho (execução de operações relativas aos problemas de missão e gerência)

- Reuniões com todos os funcionários para repasse do andamento dos trabalhos (só até a conclusão do momento explicativo).

- Cartazes/murais para divulgação dos resultados (só no início do processo)

- Seminário com todos os funcionários para discussão da Missão do CSE.
- Apresentação sintética do enfoque do PES ao colegiado de gestão

- Oficinas para seleção e processamento dos problemas, as primeiras com todas as chefias, representantes da população e associação de funcionários e as demais em grupos de trabalho

- Assembléias para discussão dos resultados parciais

- Reuniões com grupo de direção ampliado

- Idem

- Seminário com todos os gerentes 
cício de construção de uma 'imagem de futuro' que serviria de parâmetro para a seleção de problemas enquanto obstáculos ao alcance do futuro desejado. Contudo, observamos nas duas instituições que os problemas identificados são, principalmente, o resultado da aplicação do brainstorm (tempestade de idéias), não se relacionando diretamente a obstáculos para o alcance da imagem de futuro. Posteriormente avaliamos que esta dissociação pode ter sido decorrente de contradições entre as duas técnicas, já que a primeira pressupõe um exercício mais racional de identificação de problemas, enquanto a outra estimula a livre associação.

Outra adaptação importante foi feita no Protocolo de Seleção de Problemas sugerido por Matus, introduzindo-se o critério de impacto na qualidade da assistência à saúde e não utilizando outros critérios que avaliamos como mais adequados para a perspectiva do nível central de governo (maturação; inovação ou continuidade; impacto regional e balanço político).

Por fim, uma última observação refere-se à noção de momento trabalhada por Matus, que destaca a não-linearidade, ou seja, a interpenetração dos mesmos. Este fenômeno se verificou nas duas experiências, conforme pode ser visto no quadro apresentado. No Hospital, esta foi uma estratégia especialmente adotada no processo, o que permitiu maior aproximação entre o tempo metodológico e o tempo institucional. Por exemplo, ao mesmo tempo em que se desenvolvia o desenho do plano (momento normativo), algumas operações menos sensíveis aos cenários já iam sendo implementadas (momento tático-operacional) e outras passavam pela análise de viabilidade (momento estratégico). Isto possibilitou aumentar a velocidade de respostas, bem como a coesão em torno do plano, uma vez que permitiu a visualização do 'fazer'.

\section{Resultados}

Os quadros a seguir sintetizam os resultados obtidos com o processo de planejamento estratégico nas duas instituições. O primeiro trata particularmente dos resultados do processamento técnico-político dos problemas selecionados e também expressa, através da qualidade deste processamento, a capacidade gerencial das instituições. Em função dos limites de espaço para a publicação, o quadro só contém os vetores de descrição dos problemas e os nós críticos, tendo-se excluído os demais elemen- tos da explicação situacional dos problemas. Do mesmo modo, apenas parte das operações foram incluídas.

O segundo refere-se a resultados mais gerais e finalísticos, que remetem à possibilidade de ampliação da capacidade gerencial das instituições a partir do processo de planejamento estratégico. Estamos utilizando o termo 'capacidade gerencial' com um significado mais amplo, equivalente ao conceito de capacidade de governo trabalhado por Matus (1993) (Tabela 2).

Com relação aos resultados do processamento técnico-político dos problemas, várias questões devem ser observadas.

Em primeiro lugar merecem atenção os tipos de problemas selecionados. Nas duas experiências, observamos que a quase totalidade dos problemas diz respeito a aspectos internos à instituição, ou melhor, ao que Matus denomina "problemas intermediários". O único problema que não se encaixa totalmente nesta categoria foi aumento da demanda reprimida, selecionado pelo Centro de Saúde, eque pode ser situado na fronteira entre um 'problema final', ou seja, ligado à missão da instituição e um problema intermediário. É importante destacar que no Hospital foram levantados alguns problemas finais, agrupados nos enunciados produção e qualidade assistencial deficiente e inserção deficiente do HRPS no SUS e na comunidade. Embora não priorizados naquele momento, a identificação destes problemas indica a sensibilidade dos profissionais para as questões finais da organização.

Contudo, consideramos que, do ponto de vista da capacidade gerencial, a dificuldade em identificar e/ ou priorizar problemas finais revela uma limitação, na medida em que pode significar restrições na compreensão da missão e, conseqüentemente, prejuízos para a qualidade das propostas de intervenção, inclusive para aquelas relativas aos problemas intermediários.

Com relação à natureza dos problemas selecionados nas duas instituições, observamos várias semel hanças, embora a forma de recorte, ou seja, sua abrangência ou maneira de definição tenham sido diferentes. Tomemos como exemplo o primeiro problema, que em ambas as instituições refere-se à gerência, mas, enquanto o Centro de Saúde definiu-o como um problema amplo de planejamento e gestão, o recorte dado pelo Hospital envolve questões referentes à missão, já que seu enunciado relaciona a gerência aos objetivos e resultados. Por outro lado, o Centro de Saúde trata a questão da missão como um problema à parte, embora na explicação de ambos os problemas - gerên- 
Tabela 2

Quadro comparativo dos principais resultados do processamento técnico-político dos problemas (de maio de 1995 até agosto de 1996$)$

\begin{tabular}{|c|c|}
\hline Centro de saúde & Hospital \\
\hline $\begin{array}{l}\text { Problema 1: deficiência dos mecanismos de gerência, } \\
\text { planejamento, controle e avaliação }\end{array}$ & $\begin{array}{l}\text { Problema 1: gerência sem definição de objetivos } \\
\text { e não voltada para resultados }\end{array}$ \\
\hline Vetor de Definição do Problema (VDP): & Vetor de Definição do Problema (VDP): \\
\hline $\begin{array}{l}\text { Desequilíbrio entre as atividades planejadas e emergenciais; } \\
\text { ausência de acompanhamento e avaliação das atividades; } \\
\text { desorganização do trabalho na área administrativa; desinformação } \\
\text { dos funcionários quanto às decisões tomadas; representatividade } \\
\text { qualitativamente deficiente do CD/CSE; absentísmo e } \\
\text { impontualidade; descumprimento das atividades e decisões sem } \\
\text { justificativas aceitáveis; saída não planejada de pessoal para } \\
\text { participação em cursos, treinamento etc.; processos de trabalho } \\
\text { lentos e ineficazes; espaços coletivos esvaziados; falta de material } \\
\text { de consumo }\end{array}$ & $\begin{array}{l}\text { Lentidão na tomada de decisões; dia-a-dia repleto de urgências; } \\
\text { produção, custos e faturamento hospitalares desconhecidos; vigilância e } \\
\text { limpeza inadequadas; alto percentual de suspensão de cirurgias; baixa } \\
\text { taxa de ocupação nas clínicas cirúrgicas; tmp elevado; pacientes com } \\
\text { escaras nas enfermarias; alta taxa de mortalidade neonatal; inadequação } \\
\text { da formação de residentes; desconhecimento das expectativas e opiniões } \\
\text { da clientela }\end{array}$ \\
\hline Nós Críticos: & Nós Críticos: \\
\hline $\begin{array}{l}\text { Nc1: inexistência de um projeto específico para o CSE que articule } \\
\text { ensino, pesquisa e assistência }\end{array}$ & Nc1: missão do hospital não compartilhada internamente. \\
\hline Nc2: falta de um sistema de planejamento & Nc2: planejamento precário nos diversos setores e serviços \\
\hline Nc3: despreparo dos profissionais para a gerência & Nc3: inexistência de sistema de monitoramento e prestação de contas \\
\hline Nc4: sistemas de informação inadequado & Nc4: inexistência de incentivo por desempenho \\
\hline \multicolumn{2}{|l|}{ Nc5: falta de mecanismos eficientes de comunicação } \\
\hline \multicolumn{2}{|l|}{$\begin{array}{l}\text { Nc6: falta de um sistema de acompanhamento, avaliação, supervisão } \\
\text { e cobrança do trabalho }\end{array}$} \\
\hline Operações: & O perações: \\
\hline $\begin{array}{l}\text { Op 1: definir um projeto específico para o CSE contemplando as } \\
\text { atividades de assistência, ensino e pesquisa (ação 1.1: realizar um } \\
\text { seminário para definição do projeto) (esta operação é comum aos } \\
\text { problemas } 1 \text { e } 2 \text { ) }\end{array}$ & $\begin{array}{l}\text { Op 1: definir e divulgar a missão do HRPS internamente (ação1.6: definir } \\
\text { objetivos e metas para os diversos serviços de acordo com a missão } \\
\text { traçada para o hospital) }\end{array}$ \\
\hline $\begin{array}{l}\text { Op8: definir um programa de capacitação de gerentes nas diversas } \\
\text { áreas do CSE }\end{array}$ & $\begin{array}{l}\text { O p3: montar sistema de informações gerenciais: desenvolver subsistema } \\
\text { de avaliação de custos e faturamento }\end{array}$ \\
\hline $\begin{array}{l}\text { Op 11: criar uma coordenação técnica (...) para a avaliação contínua } \\
\text { do CSE }\end{array}$ & $\begin{array}{l}\text { Op5: implantar programa de capacitação gerencial (ação5.1: realizar } \\
\text { seminário de desenvolvimento gerencial com chefes de serviço) }\end{array}$ \\
\hline
\end{tabular}

cia e missão - apareça a forte inter-relação entre eles através de 'nós explicativos' (causas) comuns.

A descrição do problema de gerência/ objetivos - VDP - realizada pela equipe do hospital valorizou em especial resultados finais da própria assistência, talvez para compensar a nãoseleção do problema sobre deficiência na qualidade. Já no Centro de Saúde, chama a atenção, na descrição do problema de gerência, a preocupação com a representatividade do Conselho Departamental e com o esvaziamento de outros espaços coletivos, indicando uma compreensão estratégica sobre a gerência por uma parte do grupo encarregado do processamento do problema. Por outro lado, é importante destacar que a amplitude com que o problema foi recortado - abrangendo planejamento, controle e avaliação - é resultado de uma orientação da assessoria no processo de agrupamento dos problemas. Ainda que todos os problemas relativos à avaliação ou controle tenham sido levantados pelos próprios participantes, não havia por parte do grupo, no início, uma visão integrada da relação entre eles.

No que diz respeito ao problema relativo à missão, destaca-se em sua descrição a dificuldade que o Centro de Saúde vivencia em desenvolver as áreas de ensino e pesquisa e realizar sua articulação com a assistência. Esta questão é muito importante na medida em que expressa os desafios que se apresentam em função de sua inserção num centro de excelência em ciência e tecnologia como a Fiocruz. Cabe tam- 
Tabela 2 (continuação)

\begin{tabular}{ll}
\hline Centro de saúde & Hospital \\
\hline $\begin{array}{l}\text { Problema 2: indefinição dos objetivos do CSE em relação à missão } \\
\text { institucional (da Fiocruz) }\end{array}$
\end{tabular}

Vetor de definição do problema:

Parte dos funcionários não valorizam as atividades de ensino e pesquisa; baixos índices de produtividade segundo os critérios de uma unidade somente assistencial; baixos índices de produção científica, desarticulação da atividade assistencial em relação ao ensino e à pesquisa; falta de critérios para a utilização do tempo para as práticas de assistência, ensino e pesquisa; inexistência de critérios de prioridade para a organização da atividade assistencial; falta de entrosamento das atividades extra-muro com as intra-muro; limitação das atividades de vigilância epidemiológica ao controle das doenças infecciosas e dst; redução do trabalho das agentes de saúde

\section{Nós Críticos:}

$\mathrm{Nc1}$ : indefinição do perfil assistencial do CSE

Nc2: indefinição de um projeto de ensino e pesquisa próprio do CSE

Nc3: inexistência de mecanismos de acompanhamento e avaliação das condições de vida e saúde da população alvo

Nc4: falta de controle, acompanhamento e avaliação das ações de saúde

O perações:

Além da op 1, definida para o problema 1 acima, foi desenhada, após o seminário de missão, a seguinte operação (op13): Analisar os produtos do CSE nas áreas de assistência, ensino e pesquisa

Problema 3: política de recursos humanos inadequada

Problema 2: precariedade da política de recursos humanos no HRPS

Vetor de Definição do Problema:

Insuficiência qualitativa e quantitativa de pessoal (desdobrado em 16 indicadores); absenteísmo, insatisfação financeira, pessoal e profissional

\section{Nós Críticos:}

Ncl: falta de critérios definidos para seleção, recrutamento e liberação dos servidores externa e internamente

Nc2: inexistência de política de educação continuada

Nc3: sistema de avaliação de desempenho inexistente

$\mathrm{Nc4}$ : falta de profissionais com preparo em rh

Nc5: não reposição de pessoal

$\mathrm{Nc6}$ : processo de trabalho desgastante e desumanizado

Operações:

(não foram desenhadas operações para este problema)
Vetor de Definição do Problema:

Recursos humanos despreparados, má distribuição de rh; desvio de função muito freqüente; desempenho insatisfatório das tarefas; não-cumprimento da carga horária

Nós Críticos:

$\mathrm{Ncl}$ : ausência de mecanismos de coordenação entre rh e os setores

Nc2: indefinição das funções e atribuições da divisão de rh

Nc3: falta de um sistema de incentivo por produção

Operações:

Op1: definir as funções e atribuições e elaborar plano de trabalho para o drh 
Tabela 2 (continuação)

\begin{tabular}{|c|c|}
\hline Centro de saúde & Hospital \\
\hline Problema 4: processo de trabalho inadequado e desorganizado & $\begin{array}{l}\text { Problema 3: inadequada organização do processo de trabalho } \\
\text { inter e intra-setorial }\end{array}$ \\
\hline Vetor de Definição do Problema: & Vetor de Definição do Problema: \\
\hline $\begin{array}{l}\text { Não-cumprimento de algumas rotinas (como preenchimento de } \\
\text { exames e prontuários, normas de programas, marcação de consultas } \\
\text { e agendamento, prazos para solicitação de serviços administrativos); } \\
\text { processos indefinidos e inadequados (inexistência de padronização } \\
\text { de conduta na assistência, interrupção constante das atividades etc.) }\end{array}$ & $\begin{array}{l}\text { Lentidão nos processos administrativos; descontrole de recursos materiais } \\
\text { e financeiros; serviços desorganizados (arquivo, almoxarifado, lavanderia } \\
\text { etc.); conflito entre os serviços }\end{array}$ \\
\hline Nós Críticos: & Nós Críticos: \\
\hline $\begin{array}{l}\text { Nc1: falta de mecanismos de controle e avaliação das rotinas } \\
\text { e processos de trabalho }\end{array}$ & Nc1: mecanismos de coordenação inter e intra-setorial insuficientes \\
\hline Nc2: desinformação e despreparo no desempenho do trabalho & Nc2: indefinição de responsabilidades \\
\hline Nc3: rotinas e normas de serviços desatualizadas e/ou inexistentes & Nc3: normas e rotinas inadequadas intra e interserviços \\
\hline Operações: & Operações: \\
\hline \multirow{3}{*}{$\begin{array}{l}\text { Optou-se por conhecer melhor o problema através de um } \\
\text { levantamento dos processos de trabalho }\end{array}$} & Op1: redefinição de mecanismos de coordenação e comunicação \\
\hline & $\begin{array}{l}\text { Op2: definição de atribuições e responsabilidades dos níveis gerenciais } \\
\text { (a1: realização do seminário gerencial) }\end{array}$ \\
\hline & $\begin{array}{l}\text { Op3: revisão dos processos de trabalho, buscando revisão com } \\
\text { perspectiva de descentralização e não-fragmentação de } \\
\text { responsabilidades }\end{array}$ \\
\hline
\end{tabular}

Problema 4: inadequação dos processos de aquisição de materiais e equipamentos e sua manutenção

Vetor de definição do problema:

Lentidão no conserto de equipamentos; equipamentos obsoletos ou inexistentes; falta de material de consumo; materiais de má qualidade

Nós críticos:

$\mathrm{Ncl}$ : inadequada política de manutenção preventiva e corretiva de equipamentos

Nc2: inexistência de uma política de aquisição de equipamentos

Nc3: deficiência no sistema de abastecimento

Nc4: ausência de mecanismos de controle de qualidade de materiais

O perações:

Op1: normalização/definição do que comprar

Op2: definição do quantitativo de materiais

Op3: definição da periodicidade das compras

Op5: implantar comissão de controle de qualidade de materiais

op6: implantar gerenciamento da manutenção preventiva e corretiva de equipamentos biomédicos 
Tabela 2 (continuação)

\begin{tabular}{|c|c|}
\hline Centro de saúde & Hospital \\
\hline \multicolumn{2}{|l|}{ Problema 5: aumento da demanda reprimida } \\
\hline \multicolumn{2}{|l|}{ Vetor de Definição: } \\
\hline \multicolumn{2}{|c|}{$\begin{array}{l}\text { Aumento da fila; diminuição da capacidade de atendimento } \\
\text { da demanda espontânea; diminuição da capacidade de atendimento } \\
\text { de consulta agendada }\end{array}$} \\
\hline \multicolumn{2}{|l|}{ Nós Críticos: } \\
\hline \multicolumn{2}{|l|}{$\mathrm{N} c 1$ : modelo de agendamento inadequado } \\
\hline \multicolumn{2}{|c|}{ Nc2: falta de canais de informação/comunicação do CSE com o usuário } \\
\hline \multicolumn{2}{|c|}{ Nc3: falta de sistema de cadastramento contínuo (dos usuários) } \\
\hline \multicolumn{2}{|c|}{ Nc4: não-estabelecimento de prioridades no atendimento } \\
\hline \multicolumn{2}{|l|}{ O perações: } \\
\hline \multicolumn{2}{|c|}{$\begin{array}{l}\text { Op2: reorganizar o atendimento (ação 2.1: revisar, redefinir e implantar } \\
\text { normas de agendamento por ações programáticas) }\end{array}$} \\
\hline \multicolumn{2}{|c|}{$\begin{array}{l}\text { Op3: rever os mecanismos e canais de comunicação (operação comum } \\
\text { aos problemas } 1 \text { e 5) }\end{array}$} \\
\hline Op 4: criar um sistema de cadastramento contínuo & \\
\hline
\end{tabular}

bém destacar o fato de o Centro de Saúde ter selecionado como um dos nós críticos deste problema a inexistência de mecanismos de acompanhamento e avaliação das condições de vida e saúde da população alvo, expressando uma preocupação com o objetivo último, que é a situação de saúde da população.

Analisando as propostas de intervenção sobre os problemas de gerência e missão nas duas instituições, nota-se que al guns nós críticos indicam a intervenção sobre áreas semeIhantes. Neste sentido, podem ser ressaltados a precariedade do sistema de planejamento, como também o sistema de monitoramento e avaliação, que tiveram propostas parecidas. No Hospital, a velocidade e o nível de responsabilidade na implementação das ações relacionadas ao problema de missão foram maiores comparativamente aos demais problemas. As operações foram desdobradas até o nível de atividade. Como exemplo, o alto percentual de suspensão de cirurgias, que foi um dos descritores deste problema, passou a ser monitorado por clínica e por causa. Algumas intervenções foram desencadeadas e após quatro meses houve queda significativa do percentual. No Centro de Saúde, embora apontada como prioritária a questão da missão, não se chegou ainda a uma definição mais clara dos objetivos da instituição, mesmo após realização de seminário previsto para este fim.

As ações desenvolvidas nos últimos seis meses, nas duas instituições, foram centradas fortemente no âmbito da missão/ objetivos, o que envolve uma dimensão estratégica para o desenvolvimento da organização e andamento do plano. Do ponto de vista teórico, vale a pena ressaltar como fundamental, na compreensão de Matus sobre o funcionamento das organizações, as regras de direcionalidade, ou seja, aquelas que dizem respeito aos objetivos e funções das organizações.

A questão de recursos humanos foi enunciada de forma muito semelhante, embora a descrição feita pelo Centro de Saúde tenha sido muito detal hista e englobado a insatisfação dos profissionais, o que não aparece na descrição do Hospital.

O problema referente a processos de trabaIho teve um enunciado semelhante nas duas instituições, observando-se, no entanto, diferenças com relação a sua descrição. No caso do Centro de Saúde, houve certa dificuldade na descrição, que acabou por se superpor ao próprio enunciado. No Hospital, a descrição destacou aspectos que se aproximam do problema de gerência tal como descrito pelo Centro de Saúde.

Vale a pena comentar ainda que, em ambas as instituições, houve dificuldades para a construção da explicação e, conseqüentemente, para a elaboração de propostas de intervenção sobre o problema de processo de trabalho, em parte devido ao conhecimento insuficiente dos participantes sobre o problema e também, por outro lado, às limitações do próprio método 
PES para intervir na organização propriamente dita de processos de trabalho. Isto levou à busca de outras estratégias para a continuidade do processamento. No hospital, partindo-se de uma discussão teórica sobre metodologias de intervenção nos processos de trabalho, optouse por analisar e reorganizar, como experiência piloto, o processo relacionado a contratos de serviços, por envolver diversos setores e representar um desafio para aumentar a responsabilidade e integração institucional. No Centro de Saúde, ao contrário, a estratégia utilizada inicialmente foi a realização de um levantamento, setor por setor, de todos os fluxos e processos de trabal ho, de modo a obter melhor conhecimento dos problemas existentes previamente à intervenção. Em ambos os casos, no entanto, essas estratégias foram posteriormente complementadas, associando-se análises segmentadas de processos de trabalho a recortes mais integradores/ intersetoriais, onde tais processos aparecem mais nitidamente relacionados aos produtos/ objetivos das instituições. É importante ressaltar que, tanto no Hospital, como no Centro de Saúde, a intervenção sobre este problema passou a ser realizada em conjunto com as propostas relativas ao problema de missão/ objetivos.

Outra observação relevante diz respeito ao problema de inadequação dos processos de aquisição de materiais e equipamentos e sua manutenção, selecionado pelo Hospital talvez devido à importância que esta questão tenha representado para a instituição naquele momento. Este problema, no nosso entendimento, é um desdobramento daquele relativo à organização do processo de trabalho interno, constituindo-se num segmento mais estruturado deste. No entanto, dependendo da forma como é recortado e explicado, podem ser ressal tados aspectos mais ou menos passíveis de intervenções normatizadas. No caso do hospital, o que se observou é que o processamento do problema deu origem a uma explicação abrangente, compreendendo nós críticos, em sua maioria, pouco estruturados. Todavia, o único nó crítico que até o momento teve operações implementadas é o de deficiência no abastecimento de materiais de consumo, o mais estruturado dos quatro, embora muito estratégico, já que de sua solução depende a possibilidade de cumprimento da missão do hospital. De todo modo, a abrangência do recorte e da explicação do problema deu origem a um plano de intervenção muito amplo, dificultando a implementação das operações.

Uma observação geral importante diz respeito ao impacto simultâneo de algumas pro- postas em vários problemas. Tal fato pode ser explicado, por um lado, pela existência de nós críticos comuns a vários problemas, como, por exemplo, 'falta de um sistema de incentivo por produção', comum aos problemas de Recursos Humanos e Gerência sem Definição de Objetivos, do Hospital, e 'inexistência de um projeto específico para o Centro de Saúde que articule ensino, pesquisa e assistência', do problema de Gerência, que, por sua vez, superpõe-se a dois nós críticos do problema de missão. Por outro lado, este impacto pode ser explicado também pela estreita inter-relação entre os diversos problemas selecionados.

Passaremos agora a considerar os resultados a partir da possibilidade de impacto na capacidade gerencial das instituições (Tabela 3).

O primeiro comentário a ser destacado refere-se aos tempos gastos nesses processos de planejamento estratégico, já que a velocidade é um fator importante a ser considerado na capacidade de resposta aos problemas das organizações. Nos dois casos estudados, o que se observa, de um modo geral, é que o tempo dispendido na elaboração e execução do plano tem sido maior que o inicialmente esperado. Ainda que vários fatores possam ser associados a esta situação - a complexidade da metodologia, as respectivas estratégias de apropriação do método pela equipe de coordenação e a dificuldade de constituição de um grupo de direção mais orgânico, entre outras -, é importante levar em conta que dificilmente uma mudança de cunho mais profundo, que impacte o cotidiano da organização, possa acontecer num período curto de tempo. As resistências às mudanças, as questões relacionadas a hábitos e à cultura organizacional devem ser considerados com a devida importância. Matus, embora enfatize a necessidade de mudar a cultura das organizações, não oferece elementos teóricos suficientes para a análise e intervenção neste âmbito, sendo importante buscar o aporte de outros autores, como Habermas (Artmann, 1993).

Admitindo-se, portanto, que essa mudança tem um caráter social/cultural, não dependendo exclusivamente do método adotado, é importante reconhecer que uma das condições para que ela ocorra reside na possibilidade do processo de planejamento ser permeado pelos problemas e prioridades da vida real e cotidiana das organizações, não sendo apenas a expressão de uma formalidade. Este é um desafio que vem sendo enfrentado nos dois casos trabalhados. Observamos que a complexidade do método e as exigências que apresenta para o processamento dos problemas têm representado um certo descompasso entre o tempo ne- 
Q uadro comparativo de resultados gerais (de maio de 1995 até agosto de 1996).

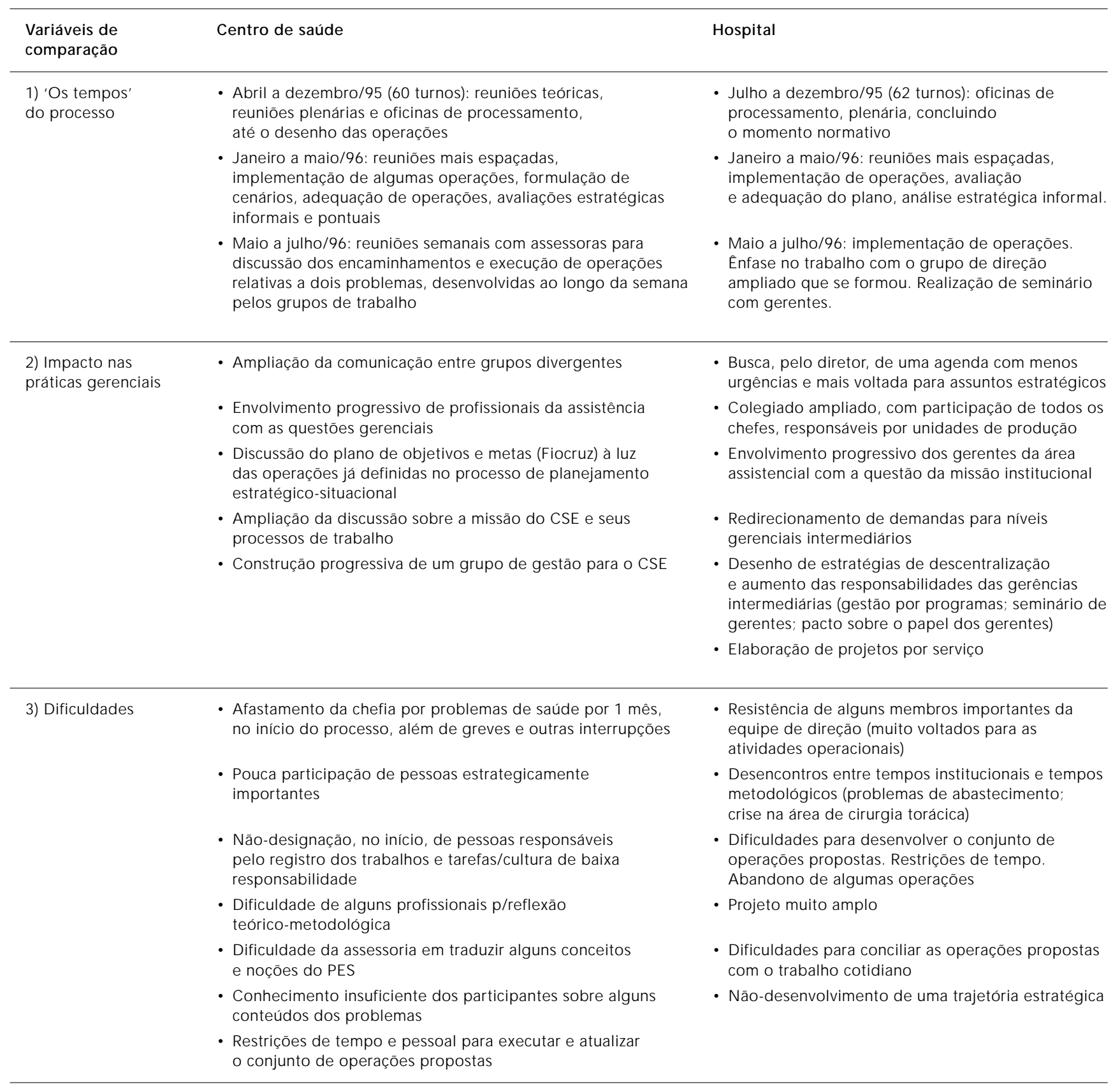

cessário para a sistematização e a dinâmica institucional cotidiana. $O$ resultado deste desencontro tem sido, por vezes, um esvaziamento dos espaços de maior sistematização metodológica, com ausência dos problemas prioritários ou emergentes a serem enfrentados pela organização. Essa situação revelou-se mais presente no Centro de Saúde, por apresentar entre outros fatores explicativos, uma menor capacidade de processamento e, conseqüente- mente, de velocidade de resposta aos problemas. Em contrapartida, na experiência do hospital, o PES se constituiu no modo de trabalhar da direção, onde, além da interpenetração dos momentos, outra estratégia voltada para maior agilidade do processo foi a utilização de préprocessamento dos problemas pela equipe de coordenação, o que reduziu significativamente o tempo de discussão e processamento nos grupos mais ampliados. 
Examinando agora as experiências com base em seu grau de sistematicidade com relação à aplicação da metodologia, é possível observar dois grandes momentos diferenciados.

Um primeiro, que correspondeu ao momento explicativo e parte do normativo, caracterizou-se por uma aplicação mais sistemática dos instrumentos metodológicos, nas duas instituições, sendo que, no Centro de Saúde, o desenvolvimento da proposta buscou maior rigor conceitual e metodológico, com menos adaptações que no Hospital.

A partir do final do momento normativo (análise das operações nos diferentes cenários), incluindo também o estratégico e o tático-operacional, observou-se uma segunda fase neste processo, quando as duas experiências, coincidentemente, passaram a se caracterizar por um processo mais informal, menos sistemático, do ponto de vista da aplicação da metodologia.

Ainda que consideremos necessária a manutenção de certo grau de sistematicidade e rigor metodológico, observamos que é importante que os participantes não se deixem aprisionar ou subordinar pelos aspectos formais do método. Esse aprisionamento seria inversamente proporcional à autonomia e capacidade propositiva dos participantes e, por outro lado, à flexibilidade na condução metodológica.

Assim, pelas características dos dois processos, observou-se, na primeira fase, uma maior subordinação dos profissionais do Centro de Saúde ao formalismo processual, comparativamente aos profissionais do hospital. Estes últimos, com maior freqüência, abriram mão de alguns passos metodológicos na busca de maior agilidade de respostas e aprofundamento de proposições, bem como souberam se utilizar do espaço de discussão para clara negociação política. No caso do Centro de Saúde, o maior formalismo pode estar ligado à menor organicidade do grupo de coordenação, ao pouco conhecimento técnico sobre o conteúdo de al guns problemas trabalhados, à menor experiência gerencial, bem como ao encaminhamento do processo dado pela assessoria.

Já na segunda fase, observamos, nas duas experiências, um processo de revisão informal do plano, que se expressou na reformulação de algumas operações sem a correspondente revisão dos conteúdos explicitados anteriormente nos diversos instrumentos metodológicos ('formatos'). Neste processo, ocorreu também, nas duas instituições, uma priorização, em termos de execução, das operações relativas à missão institucional e um 'abandono' de parte significativa do plano, que incluía operações voltadas para o enfrentamento de outros problemas.

Os fatos acima nos remetem a algumas considerações. Por um lado, evidencia-se a relativa abrangência dos planos comparativamente à capacidade de processamento das equipes envolvidas, o que pode ser explicado por fatores que vão desde a orientação metodológica no recorte e seleção dos problemas a questões relativas à insuficiência quantitativa e qualitativa de pessoal e aos ainda baixos níveis de responsabilidade - no sentido trabalhado por Matus na Teoria das Macroorganizações (Matus, 1993; Rivera, 1995; Artmann, 1993). Por outro lado, é necessário reconhecer - como inerente à introdução de processos de mudança de forma participativa nas organizações - a real sobrecarga advinda da necessidade de compatibilizar a execução das atividades relativas à continuidade do funcionamento da organização com as novas demandas oriundas do processo de mudança.

De todo modo, embora seja necessário evitar um aprisionamento ao formalismo processual do método, deve ser considerado que um dos objetivos dessa metodologia é aumentar a capacidade de governo das equipes envolvidas, para o que o emprego de seus instrumentos pode ser uma das condições. Nas duas experiências não se conseguiu, até o momento, desenvolver o plano de forma mais sistemática após o desenho das operações. Assim, não se chegou a analisar, por exemplo, o impacto dos cenários sobre as operações. Do mesmo modo, as análises estratégicas não sistemáticas não conduziram à montagem de uma trajetória estratégica mais global para a execução do plano. As conseqüências podem se manifestar, entre outros aspectos, na falta de ligação ou coerência entre as decisões do dia-a-dia e a situaçãoobjetivo pretendida.

Nesta discussão em torno da necessidade de maior ou menor sistematização, não se pode deixar de considerar também a capacidade de análise estratégica e gestão já acumulada pelas equipes. No caso do Hospital, a despeito de existirem condições mais favoráveis a um processo mais sistemático, do ponto de vista metodológico, dadas pela inserção da assessora como membro da equipe de direção, acabou-se optando, de certo modo, por um processo mais informal, na medida em que a equipe de direção formada reunia um grupo de profissionais com boa capacidade de análise estratégica e formulação, o que, esperava-se, minimizaria as perdas possíveis relativas a processos menos sistemáticos. 
Considerando finalmente a possibilidade de construção de um ator que expresse um projeto coletivo, deve ser ressaltado que na experiência do Hospital foi visível o processo de ampliação do grupo de coordenação, constituindo uma instância de gestão com um projeto definido. No caso do Centro de Saúde, observa-se que o compromisso e identificação do grupo em torno do processo tem sido construído mais lentamente.

Observamos, nas duas experiências, dificuldades em maior ou menor grau com relação ao aumento do nível de responsabilidade para com o processo, ritmo e cumprimento das tarefas acordadas, bem como dificuldades quanto à explicitação e até mesmo a formulação dos diferentes projetos em jogo no interior das organizações. Poderíamos considerar como principais hipóteses explicativas a pouca organicidade política dos grupos e sua dificuldade em se constituírem enquanto atores e, ainda, o predomínio da cultura da não-responsabilidade como regra nas instituições públicas (Matus, 1992).

Por fim, consideramos importante destacar que existem diferentes formas de envolvimento dos profissionais com o processo de planejamento e o projeto institucional. A adesão ao projeto/plano não pode ser construída com base apenas na participação dos profissionais nos momento de discussão mais sistemática do plano/ projeto, mas deve expressar-se também no seu envolvimento cotidiano com a realização das operações/ações e com a busca dos resultados.

\section{Considerações finais}

Uma consideração mais geral diz respeito à categoria ator. Ao longo das experiências aqui relatadas, sentimos dificuldades para trabalhar com esta categoria do ponto de vista intra-institucional. Matus dá pouca ênfase, em sua conceituação, ao papel desempenhado por 'atorespersonalidade' no interior das organizações profissionais que individualmente apresentam forte capacidade de influência e condução de determinados processos, em função, não necessariamente, dos cargos que ocupam. Outro aspecto que mereceria um tratamento mais diferenciado na identificação dos atores intrainstitucionais seria o critério - imprescindível para Matus - de existência de um projeto político claramente definido. O que observamos são situações em que 'atores-personalidade', nem sempre com um projeto político muito claramente definido, têm capacidade para in- terferir no processo, obstaculizando por vezes a implementação de propostas importantes.

Do ponto de vista da constituição de um ator capaz de expressar um projeto coletivo partindo de diferentes racionalidades, visões e interesses presentes na organização, é importante destacar que as duas experiências sinalizam positivamente neste sentido. Observa-se a criação e/ ou ampliação de canais de comunicação internos e a progressiva formação de grupos mais orgânicos em torno de problemas institucionais relevantes. No entanto, não podemos perder de vista que este é o desafio principal das experiências que buscam imprimir mudanças substantivas nos processos institucionais. Nos casos estudados, as dificuldades já relatadas ao longo deste artigo - como os ainda baixos níveis de responsabilidade institucional, o domínio de uma prática de improvisação sobre o planejamento, entre outras - expressam a complexidade desses processos de mudança.

Outro aspecto que merece ser considerado refere-se à relação entre a abrangência do plano, a capacidade de processamento das equipes e a possibilidade de se implementar um plano estratégico de ação. Ainda que se reconheçam as limitações na capacidade de processamento dos problemas vividas pelas instituições, não se pode deixar de considerar as inter-relações entre os diversos problemas e, conseqüentemente, o risco de diminuição e até mesmo perda do impacto das intervenções sobre os processos institucionais, quando estas se reduzem ao enfrentamento de apenas um ou dois problemas. Este é um ponto crítico que, nas experiências estudadas, merece ser mais bem acompanhado com a continuidade da investigação.

Outra questão importante diz respeito à relação entre o grau de sistematicidade com que se desenvolve o processo de planejamento e a capacidade de análise estratégica. Se, por um lado, a sistematização pode contribuir para ampliar a visão estratégica, por outro lado, a necessidade de respostas vel ozes e a complexidade do método, entre outros fatores, às vezes não permitem o aprofundamento da análise a partir do instrumental metodológico. Assim, ainda que se reconheça a boa capacidade de análise estratégica de alguns participantes, permanece como desafio - não só do ponto de vista das experiências relatadas - a busca de mecanismos ou formas de simplificação do método que, ao mesmo tempo em que permitam sua apropriação por um maior número de participantes, elevem a capacidade de análise e formulação estratégica das equipes. Tal simplificação deve ser compreendida, portanto, 
como fator essencial para a ampliação da comunicação interna e, conseqüentemente, para a possibilidade de construção de um projeto coletivo e estratégico.

Além das questões acima, ficam especialmente registradas, como intenção de continuidade de nossa investigação, o exame de possí-

\section{Referências}

ARTM ANN, E., 1993. O Planejamento Estratégico Situacional: A Trilogia Matusiana e uma Proposta para o Nível Local de Saúde (Uma Abordagem Comunicativa). Dissertação de Mestrado, Rio de Janeiro: Escola Nacional de Saúde Pública, Fundação Oswaldo Cruz.

AZEVEDO, C. S., 1993. A Gerência Hospitalar: A Visão dos Diretores de Hospitais Públicos do Município do Rio de Janeiro. Dissertação de Mestrado, Rio de Janeiro: Instituto de Medicina Social, Universidade do Estado do Rio de Janeiro.

AZEVEDO, C. S., 1995. Gestão hospitalar: a visão dos diretores de hospitais públicos do Município do Rio de Janeiro. Revista de Administração Pública, 29:33-58.

FONSECA, A. S. A. F., 1996. O Planejamento Estratégico-Situacional e o Centro de Saúde-Escola Germano Sinval Faria - Contribuição para o Workshop "Construindo um Modelo de Assistência, Ensino e Pesquisa". Rio de Janeiro: Escola Nacional de Saúde Pública (mimeo.)

HABERM AS, J., 1987. Teoria de la Acción Comunicativa. Madri: Editora Taurus.

MATUS, C., 1993. Política, Planejamento e Governo. Brasília: IPEA. veis diferenças quanto aos limites e possibilidades de adoção do enfoque de planejamento estratégico em organizações de saúde de distintos níveis de complexidade e o estudo da especificidade que o caráter público das organizações possa conferir aos processos de planejamento e gestão.
MATUS, C., 1994a. Sobrela Teoria de las Macroorganizaciones. Revista Pes, 3.

MATUS, C., 1994b. El PES en la Practica. Caracas: Fundación ALTADIR (mimeo.)

MATUS, C., 1994c. Guia de Analisis Teórico. Curso de Governo e Planificação. Caracas: Fundación ALTADIR.

MINTZBERG, H., 1989. Mintzberg on Management: Inside our StrangeWorld of Organizations. New York: The Free Press.

RIVERA, F. J. U., 1995. Agir Comunicativo e Planejamento Social: Uma Crítica ao Enfoque Estratégico. Rio de Janeiro: Editora Fiocruz.

SÁ, M. C., 1993. Planejamento Estratégico em Saúde: Problemas Conceituais e Metodológi cos. Dissertação de Mestrado, Rio de Janeiro: Escola Nacional de Saúde Pública, Fundação Oswaldo Cruz.

SÁ, M. C. \& ARTM ANN, E., 1994. O planejamento estratégico em saúde: desafios e perspectivas para o nível local. In: Planejamento e Programação Local da Vigilância da Saúde no Distrito Sanitário (E. V. Mendes, org.), pp. 19-44, Brasília: OPAS.

TAVARES, M. F. L.; VICENTIN, G.; FONSECA, A. S. A.; PORTO, C. B. M.; SOARES, S. M. \& ADESSE, L., 1996. CSE: Construindo um Novo Modelo de Assistência, Ensino e Pesquisa. Rio de Janeiro: Escola Nacional de Saúde Pública (mimeo.) 